\title{
Planting the Eco-Humanities? Climate Change, Poetic Narratives, and Botanical Lives
}

\author{
John Charles Ryan
}

Honorary Research Fellow in the Department of English and Cultural Studies at the University of Western Australia. ORCID http://orcid.org/oooo-0oo1-5102-4561. Email: john.c.ryan@uwa.edu.au

Received May 15, 2016; Revised July 10, 2016; Accepted July 10, 2016; Published August 18, 2016

\begin{abstract}
This essay offers an initial attempt to think through how some of the ideas emerging from the new field of "critical plant studies" (CPS) can elucidate, deepen, or challenge aspects of climate change discourse. Across the globe, the deleterious impacts of climate change on plants are increasingly documented by scientists. However, despite their fundamental role in the carbon cycle of the biosphere and the disruption of botanical communities in the wake of climate disturbance, plants occupy a marginal position in the narratives told about climate change. This assertion will be explored, substantiated, and expanded more concretely in reference to the "Keep It In the Ground Campaign" curated by the newspaper The Guardian in 2015. The stories circulating in the public imagination about climate change and that provoke debate, action, and reflection can be enhanced through the invigorated understandings of the vegetal world offered by the emerging field of critical plant studies (CPS).
\end{abstract}

Keywords: Critical Plant Studies, Ecopoetics, Climate Change Narratives, Activism.

\section{Introduction}

Plants are our most cherished and precious foods, medicines, fibers, decorations, and totems (Clarke, 2011). Human beings breathe with plants every moment of our lives through a kind of perpetual embodied dialogue: oxygen in, carbon dioxide out. Vegetative life accounts for nearly 99.9\% of the planet's biomass (Mazzolai \& Mancuso, 2013, p. 1). Yet we often forget that plants have their own lives to lead, including their desires, comforts, and goals. Due to their sessile lifestyles, silences, ubiquities, and uncanny abilities to regenerate and proliferate, plants can be too often dismissed or relegated to the categories of disposable things, mute materials, unsensing automatons, or aesthetic objects (Ryan, 2012). By calling attention to the sensitivities of plant life and the intellectual histories that have subjugated them-from tall trees to prostrate herbs of all forms, shapes, colors, and sizes-the emerging interdisciplinary field of critical plant studies (CPS) asserts the pressing need to devise frameworks for governing the ethics of human interactions with the botanical world (see, for example, Marder, 2013; Vieira, Gagliano, \& Ryan, 2016). These ethical frameworks counterpoise anthropocentric tendencies to treat, conceive of, and categorize plant life either as speechless material for consumption or as beautiful objects for sensory appreciation (Hall, 2009). New understandings of plants-as percipient, intelligent beings with the ability to remember, learn, adapt, and behave (Gagliano, Renton, Depczynski, \& Mancuso, 2014; Trewavas, 2014) -also problematize the utilitarian paradigm that conceptualizes

(c) AesthetixMS 2016. This Open Access article is published under a Creative Commons Attribution Non-Commercial 4.0 International License (http://creativecommons.org/licenses/by-nc/4.o/), which permits non-commercial re-use, distribution, and reproduction in any medium, provided the original work is properly cited. For citation use the DOI. For commercial re-use, please contact editor@rupkatha.com. 
the lives of plants as having value only in terms of the "ecosystem services" they confer to other, more sentient living beings (Bouma \& van Beukering, 2015).

While bringing the intrinsic rights of plants to the fore, the ethical principles forwarded by CPS research can also trigger the restructuring of discourse, leading to new possibilities for the stories we tell about plants and climate change. Hence, rather than focusing on ethics, this discussion postulates how discourse, in the form of poetic narratives, might shift to reflect-and come to be shaped by-the botanical world. In addition to the question-what can critical plant studies contribute to climate change narratives - the essay asks the following: considering plants both as primeval sources of carbon and as modern carbon sinks, and as beings inextricably linked to human survival in the Anthropocene, why do they seem to languish in the background of the stories we tell about climate change? And do they in fact languish? Has there been a failure to narrativize plants and, if so, what are the reasons for these narrative blind spots that privilege the experiences of animals and humans? Considering the vast terrain of what constitutes climate change discourse-from science and politics to fiction and film (Anshelm \& Hultman, 2015) - the scope of the discussion will be limited to narratives and, more specifically, to climate change poetry through a topical example entitled the "Keep It In the Ground" campaign. Curated by British Poet Laureate Carol Ann Duffy in 2015, this online anthology of climate change poetry was published over twenty consecutive days in the British newspaper The Guardian. Well-known actors, including James Franco and Jeremy Irons, recited some of the poems, lending greater public impact to what was essentially a narratively- and poetically-based campaign.

By way of an overview, Section 2 of the paper outlines current scientific ideas about the interrelationship between plants and climate change, while Section 3 addresses developments in critical plant studies (CPS) that build upon new scientific knowledge of plants. Section 4 shifts the focus of the discussion to climate change narratives in poetry through the "Keep It In the Ground" campaign through textual analysis of poems by Carol Ann Duffy, Alice Oswald, and others whose work featured in the short-term poetic initiative. In Section 5, the discussion concludes by postulating five ways critical plant studies (CPS) might help to recast climate change discourse by rendering narratives of all kinds (poetic, performative, journalistic, vernacular) more botanically attentive and constituted. Throughout this essay, I will aim to draw a distinction between plant life and plant lives. The former is a category of biological science based on the ideal of the species and achieved through methods of abstraction and totalization. The latter, the lives of plants, is an ontological assertion signifying the potential of plants to experience the world and carry out their lives independently of social constructions, human desires, and techno-scientific interventions.

\section{Plants, Climate Change, Resilience, and Bio-inspiration}

While the deleterious impacts of climate change on plants in many regions of the world are welldocumented (Omasa, Kai, Uchijima, \& Yoshino, 2013; Rozema, Aerts, \& Cornelissen, 2006), current scientific analysis points to the surprising resilience of botanical life in response to climatic disturbance (Parmesan \& Hanley, 2015). For example, a study based at the University of Minnesota indicated that plants can acclimate to rising temperatures while releasing only onefifth as much additional carbon dioxide than researchers had previously believed (Reich et al., 2016). The team demonstrated that plant respiration can adjust to experimental warming conditions and seasonal temperature variations. The data suggests that, with enhanced leaf thermal acclimation, plants are more adaptive and, thus, contribute less to climate warming than earlier models indicated. Moreover, researchers based at the University of Copenhagen showed 
that plant gases, or biogenic volatiles, can slow the increase of atmospheric temperatures in the Arctic (Kramshøj et al., 2016). When biogenic compounds react in the Arctic atmosphere, they extend the lifespan of the potent greenhouse gas methane while prompting the formation and growth of air particles that cool down the atmosphere. The release of volatile compounds leads to the aggregation of additional cooling particles and the subsequent formation of clouds. This phenomenon is especially important for global sustainability considering that the rate of the melting of the Greenland Ice Sheet is deeply implicated in the climate change patterns of the biosphere.

Additionally, scientists at the University of Plymouth identified the pervasive effects of anthropogenic climate change (ACC) on all aspects of global plant biology as a consequence of increased atmospheric carbon dioxide levels, hotter climate conditions, and altered precipitation patterns (Parmesan \& Hanley, 2015, p. 849). In the context of human-driven climate change, plant life tends to defy conventional models and statistical predictions concerning the biological impacts of increased carbon dioxide and temperatures, and diminished rainfall (p. 861). The misalignment between theoretical prediction and ecological adaptation is partly due to the unforeseen complexity of interactions between plants, herbivores, symbionts, competitors, and the abiotic environment. In short, science simply does not comprehend the full extent of plants' behaviors in the context of climate change. As the researchers conclude, "the typically expected responses [of plants to climate change] are generally well-understood [but] the aberrant responses [...] are now yielding greater insight into the impacts of ACC, and therefore offer the greatest prospect for improving our ability to project plant impacts into a very uncertain future" (p. 861). As a whole, these representative studies indicate that the resilience and adaptive abilities of individual plants and whole botanical communities ensure that the implications of climate change are often not those anticipated by climate scientists.

These studies further suggest that multi-faceted knowledge of plants might also facilitate human adaptation to an increasingly bleak climate future. Progressively more, the challenge for humanity is to align (and, indeed, ally) ourselves and our societies with plants in intimate concourse with their lives and within "co-constitutive relations" (Cudworth, 2016, p. 43; Haraway, 2008). Echoing this assertion, biologist Stefano Mancuso uses the term bio-inspiration to denote the application of vegetal intelligence and plant-like networks to the design of technologies and social structures, resulting in sustainable systems that are "networked, decentralized, modular, reiterated, redundant and green" (Pollan, 2013, pp. 104-105). The Plantoid project conducted by Mancuso and colleagues attempts to put the promise of bio-inspiration into practice through a number of innovative engineering initiatives (Plantoid Project, 2012). The researchers recognize that "the mechanical properties of plants, the morphology of their structures and their characteristic movements represent a goldmine of solutions that, with appropriate investigation, could be used to obtain new design rules for advanced bioinspired systems and materials in countless applications" (Mazzolai \& Mancuso, 2013, p. 1). However, despite the more botanicallyattuned approach of bio-inspired engineers, the lives of plants also require recognition, respect, and human engagement beyond their utilitarian value as "a goldmine of solutions" to climate change issues.

\section{Developments in Critical Plant Studies}

A rapidly growing body of scholarship known as critical plant studies (CPS) seeks to bring attention to the lives of plants, their intrinsic (non-utilitarian) value, and the possibilities for 
dialogic relations between humans and plants in an era of climate change and mass global extinction of floristic (and other) species. The field poses sharp critiques of long-standing conceptions of plant life in aesthetics (Ryan, 2012), critical theory (Nealon, 2015), ethics (Hall, 2009), literary studies (Laist, 2013), metaphysics and ontology (Marder, 2013), performance and politics (Vieira et al., 2016), and other areas of culture, society, and philosophy. On the whole, the field aims to accomplish for plants what human-animal studies (HAS) socially codified for animal life over twenty years (Huggan \& Tiffin, 2010; Shapiro \& DeMello, 2010). The animal rights movement of the 1970s spurred greater societal regard for animals and human interactions with them (Singer, 1975). By the 1990s, courses in human animal studies were introduced to veterinary schools and animal research institutes in North America in order to facilitate reflection on the ethical dimensions of human treatment of animals. Attributing ideas of agency, autonomy, percipience, and sentience to the non-human world strengthens the standing of beingsincluding animals and plants-historically relegated to the lower rungs of the chain of life.

Interdisciplinary CPS research pivots toward the vibrant field of plant signaling and behavior, including what scientists have called "plant neurobiology" (a contentious term considering the fact that plants lack brains as well as the neural networks found in animals) (Barlow, 2008) and another area of research termed "plant bioacoustics" (Gagliano, 2013). Generally speaking, this body of science demonstrates the long-term memory and behavior of plants in the context of their learning processes. The experimental results acknowledge plants as highly sensitive organisms that "perceive, assess, interact and even facilitate each other's life by actively acquiring information from their environment" (Gagliano, Mancuso, \& Robert, 2012, p. 3). More specifically, plant bioacoustics describes the perception and production of sound, indicating that plants emit sonic data and adapt their behaviors in response to received auditory information (Gagliano, 2013; Gagliano et al., 2012). Such an understanding of sound ecology counterpoises the traditional bioacoustic model attributing the vocalizations of plants to pressure changes and other external factors. On the contrary, recent bioacoustic research empirically affirms that vocalization in plants is an active process facilitating signaling in a manner perhaps more efficient than the chemical model of plant communication has allowed.

Although plants lack brains and neural tissues, they possess complex internal signaling networks including those involving sound. The intentional production of sound serves an ecological function by enhancing the fitness of the plant in terms of its evolutionary makeup (Gagliano, 2013, p. 1). These kinds of considerations constitute what the prominent scientist Anthony Trewavas calls "mindless mastery," a networked and distributed form of intelligence specific to plant life (Trewavas, 2002). In one study, mimosas (Mimosa pudica) ceased closing their leaves when they realized that a recurring disturbance-in this case, being dropped-led to no actually damaging outcomes (Gagliano et al., 2014). Such an experiment confirms the ability of plants to memorize information and coordinate behavioral responses. Hence, extending and building upon ideas of plant intelligence, learning, and behavior (as articulated in various areas of the biological sciences) to the humanities and social sciences, critical plant studies (CPS) attends to the life worlds of plants, including their predispositions for intention, sensing, sensation, meaning-making, memory, and forms of experience and expression. Through the integration of the humanities and sciences, plants can be understood more persuasively as agents acting uponand, indeed, transforming-art, culture, literature, politics and all activities in which human beings engage. A broad-ranging and encompassing interdisciplinary perspective on vegetal life is exceptionally important, considering the impacts of anthropogenic climate change on both plant and human wellbeing. 


\section{Climate Change Narratives: The "Keep It In the Ground" Campaign}

How might principles of vegetal percipience emerging from science (and signaled by the research into memory, learning, and behavior outlined in the previous section) contribute to climate change discourse, potentially expanding the gamut of living beings and voices included within narratives? In this regard, it is essential to consider some of the narrative forms that engage climate change issues. The last five years have marked a proliferation of climate change fictionor cli-fi-defined as "stories set in a climatically changed world, describing the human experience of such fictional futures" (Milkoreit, 2016, p. 172). Cli-fi considers the internal, psychological impacts of climate change, but also the external effects of social and ecological collapse (JohnsPutra, 2016, p. 269). The genre thematizes the political consequences of climate disturbance and the challenges to human survival instigated by anthropogenic climate change through recognizable literary forms, including parody, satire, and elegy. Also of note is the emergence of climate change theater, which dramatizes disastrous climate-related events and their aftermaths. Dramatic, performative narratives tend to navigate the internal, psychological dimensions of climate change (Johns-Putra, 2016, p. 270).

In addition to cli-fi and theater, ecopoetry (ecological or environmental poetry; or ecopoetics) provides a medium for poets to narrativize climate change. Alfred Siewers outlines four features of ecopoetry as: (1) traidic overlay, or the interrelation of sign, object, and interpretant-meaning; (2) metonymic imagery in which metaphors intertwine with the materiality of the environment; (3) time-plexity as the interpenetration of non-human temporalities and even non-time itself; and (4) environmental ethos or, following the thinking of seminal conservationist Aldo Leopold, a land ethics (Siewers, 2011, pp. 108-109). These four dimensions figure into the poetry of the "Keep It In the Ground" campaign published online in 2015, reflecting the idea that poetry augments the climate change narratives circulating in the public imagination. The curator poet Carol Ann Duffy asserts that "journalists have transmitted the warnings of scientists, but they have sometimes focussed too much on the mini-controversies and the unimportant disagreements and not enough on the big picture. That has often left readers confused" (Duffy, 2015a). In Duffy's view, climate change journalism and the science on which it is based can alienate the public by rendering the issue devoid of emotional or aesthetic content. In response, the 2o-day "anthology of poetry on climate change" features lyrical descriptions by twenty different poets promoting an environmental ethos while poetically expressing personal experiences of mourning, loss, and displacement.

However, despite its laudable intentions, the project bears a distinctly zoocentric imprint. On the whole, the poems privilege the experiences of humans and other animals-and, less frequently, water, soil, and rocks-but largely neglect plants. For instance, Duffy's poem "Parliament" is characteristic of the unconscious privileging of the zoological over the botanical in climate change narratives. The poem opens with the lines: "Then in the writers' wood / every bird with a name in the world / crowded the leafless trees" (Duffy, 2015b, 1l. 1-3). An array of bird voices and affects follow: owls grieve, magpies mock, rooks curse, cormorants speak, woodpeckers heckle, hawks swear, and nightingales intone. The poem concludes with "the golden plover, / and the albatross / telling of Arctic ice / as the cold, hard moon calved from the earth" (Duffy, 2015b, 11. 49-52). As percipient organisms, birds bear witness to climate change alongside humans. Yet cataclysm correspondingly disrupts the language of fish, which is "cut out at the root" (where the term root is figurative, rather than vegetally material, serving as a metonym for the basis of oceanic systems and the food chain) (Duffy, 2015b, p. 21). Even the oceans have fallen "mute," implying that they were able to vocalize once but have since lost the capacity: "Mute oceans. Oil 
like a gag / on the Gulf of Mexico" (Duffy, 2015b, pp. 22-23). In stark contrast, trees, such as an oak and sycamore, represent the passive contexts for the life worlds of zoological interpretants engaged in material semiosis and immersed in affective, relational states: "An owl grieved in an oak" and "a rook / cursed from a sycamore" (Duffy, 2015b, 1l. 5, 6-7). Plants are neither conferred voice-indeed the trees are merely "leafless"-nor recognized for their capacity for sentience or experience, unlike the prominent avian subjects of the poem.

My analysis is not intended as an indictment of Duffy's poem, the campaign, nor the genre of ecopoetry with its vaulted principles of environmental ethics and vision of ecological justice for all beings-floral, fungal, faunal. Rather, I wish to call attention to a predisposition in poetic works and the majority of other narrative forms to relegate vegetal life to the background of the stories we tell about climate change-as the somewhat living, somewhat dead setting for animalistic dramas in the tragic context of climate change. After all, plants can be hard to get to know, and there is, at the same time, the issue of translation: their semiosis of chemicals and corporealities does not readily align with the linguistic pronouncements we generally regard as intelligible communication. The notion of having discourse with plants is generally viewed as an absurd flight of fancy. Additionally, why should poets and other narrators presume to penetrate the inner domain of plants and interpret their responses to environmental degradation? Vegetal life is considered secret, veiled, private, cryptic, and separate to the everyday perceptual domain of humans-a conspicuous theme in Tompkins and Bird's classic though controversial book, The Secret Life of Plants (1974), the Stevie Wonder album of the same title (1979), and many subsequent books and recordings on the theme. Nonetheless, I suggest that the characterization of plants as secret or cryptic comes with the risk of marginalizing their lives as well as our responsibility for their futures as sentient non-human beings impacted by climate disturbance yet also adapting in ways specific to their vegetality.

These narrative patterns persist in poet Alice Oswald's hydrologically attuned "Vertigo"a perceptive, delicate, and imaginative elucidation of the "two minute life of rain" (1. 1), in which water is animate and the narrative is, to a degree, told from the perspective of water. In sharp contrast to acknowledging the life of water, the poem's allusions to plants are more metaphorical, incidental, and contextual. For instance, the rain witnesses "the garden in the green of its mind already drinking / And the grass lengthening" (Oswald, 2015, 11. 15-16). Although Oswald hints at the mentation of the garden, the rain ultimately is the animate force that narrates itself and its relations: "And I who live in the basement / one level down from the world / with my eyes to the insects with my ears to the roots listening" (Oswald, 2015, 11. 25-27). What is glaringly missing from Oswald's poem, from a critical plant studies perspective, is a sense for the ecological imbrications between rain, animals, plants, and other beings where all contribute their percipience to the construction of the narrative. As the science of plant signaling and behavior indicates, it is not a flight of fancy or transgression against Western epistemology for plants to speak, remember, learn, experience excitation, or express pain.

What might climate change be like from the perspective of a plant? Like many climate change narratives, the "Keep It In the Ground" campaign neglects to consider this intriguing and potentially productive question. It is never too late for poetic narratives and other genres to begin to engage with the climatically altered lives of plants vis-à-vis emerging scientific research into floristic abilities. However, no single storied instance, such as a poem or novel, should or can do everything, resulting in a communion of subjects-a narrative Noah's Ark-within the myriad limitations of verse or prose. Nonetheless, these brief examples from the campaign and my abbreviated readings do intimate that the prevailing outlook on plants-intensified in the context 
of climate change where the impacts on animals and humans are most apprehensible and, thus, mediated-is an ambivalent one. To be sure, plants do appear in our imaginations: we note their flowering, seeding, and dying back. Entering periods of dormancy or senescence, they depart from our consciousness for long stretches of time. They become the mute, unaffected, stalwart backgrounds against which the world's animalistic tensions unfold. We also tend to notice plants in their absence, for example, as a gap in a forest after a tree has been felled. In an era of exponentially intensifying climate change, species loss, and ecocultural disintegration, it is urgent that our narratives begin to intergrade with the agencies of plants and for our environmental consciousness to turn more concertedly toward the vegetal world.

\section{Conclusion: Plant-Shaped Climate Change Narratives}

The final section of this paper broadens the discussion by speculating how critical plant studies might shift the peripheral emphasis on the vegetal world in climate change narratives. Although five distinct but related ideas will be proposed, there are many more to consider as writers, scientists, and the general public become increasingly aware of the essential place of plants and botanical communities in climate change especially as emerging research into signaling and behavior overturns entrenched preconceptions of flora as passive, mute, and unfeeling. First, CPS can recast climate change narratives by bringing plants to the foreground as agents with their own modes of adaptation to, and subjective experiences of, environmental disturbance in the Anthropocene. Along these lines, consider, as models, John Wyndham's 1951 post-apocalyptic novel The Day of the Triffids (1986) in which bioengineered triffid plants exhibit aggressive forms of movement and communication; or, on a much different note, Louise Glück's Pulitzer Prize winning poetry collection, The Wild Iris (1992), presented almost entirely from the perspectives of garden plants who speak in the first person about their lives. Second, CPS can ground climate change narratives in the substance of the botanical world, thereby transforming the abstracted rhetoric of statistical predictions and scientific models into evocative material realities that affect us on a personal, emotive level. The mediation of the embodiment of plants in narratives can mirror back to us our utter physical, psychological, and spiritual interdependence with vegetal life during the ecologically unstable era we find ourselves in. In this fashion, the nineteenth-century prose writings of naturalist Henry David Thoreau in Faith in a Seed (1993) and Wild Fruits (200o) provide early examples of writing that sensorially and immersively attends to flora.

Third, concerted attention to vegetality in narratives can interject sensuous specificity, which then counterbalances and 'brings down to earth' the immense scale and abstract nature of climate change as it is theorized in many forms of discourse (e.g., in the media and in science). In this regard, ecocritic Tim Morton characterizes climate change as a "hyperobject"-a phenomenon so distributed in time and space that it scrambles everyday perception (Morton, 2013). The powers of plant scents, tastes, sensations, sounds, and sights concretize the phenomenological effects of climate change as a hyperobject while evoking our affective states in dialogic relation to other organisms. Regard, as an example, the Australian poet Les Murray's cathartic impressions of a eucalypt forest: "I go my way, looking back sometimes, looking round me; / singed oils clear my mind, and the pouring sound high up. / Why have I denied the passions of my time? To see / lightning strike upward out of the gum forest" (Murray, 2007, p. 31, 11. 28-31). Fourth, vegetal temporality enables the contemplation of time scales well beyond our limited human standard while minimizing the potential for us to become psychologically overwhelmed by the actual extent of deep geological time. Alfred Siewers refers to this phenomenon as timeplexity-the interpenetration of non-human temporalities signifying the potential for 
timelessness and states of non-time. Plants occupy a temporal milieu that is both accessible and off-limits to human apprehension of time. In this sense, vegetal life can become our ally and mentor in time, which is key to comprehending the actual extent and impact of climate change.

Fifth and finally, plants compel us to consider the dialectics of climate change and prompt us toward our own forms of social and personal adaptation. That plants are both ancient sources and modern sinks of carbon reveals that the vegetal mode of being can accommodate the messiness of human-plant-earth-animal-biosphere-time entanglements. Such a dialectics-which collapses the binarisms of nature/culture, cause/effect, us/them-can enable us to conceive of climate change in terms that resist monologic practices, rigid categorizations, and unfounded expectations. In sum, the stories circulating in the public imagination about climate change and that provoke debate, action, and reflection can be enhanced through the invigorated understandings of the botanical world offered by critical plant studies (CPS). This includes the increased representation of plant life, plant ethics, and vegetal intelligence in climate change narratives, but also involves the intrinsic reshaping of narratives into distinctly vegetal forms. On a final note, I suggest that the question of the plant is crucial for the emergence of a truly transdisciplinary environmental humanities. We might keep in mind that the exemplary transdisciplinarians Henry David Thoreau, Johann Wolfgang von Goethe, Alexander von Humboldt, Jagadish Chandra Bose, Eramus Darwin, and others understood the vitality of plants as a key to consilient forms of thinking and doing.

\section{References}

Anshelm, J., \& Hultman, M. (2015). Discourses of Global Climate Change: Apocalyptic Framing and Political Antagonisms. New York: Routledge.

Barlow, P. (2008). Reflections on 'Plant Neurobiology'. BioSystems, 92(2), 132-147.

Bouma, J., \& van Beukering, P. J. H. (2015). Ecosystem Services: From Concept to Practice. In J. Bouma \& P. J. H. van Beukering (Eds.), Ecosystem Services: From Concept to Practice (pp. 3-21). Cambridge, UK: Cambridge University Press.

Clarke, P. (2011). Aboriginal People and Their Plants. Dural Delivery Centre, NSW: Rosenberg.

Cudworth, E. (2016). Ecofeminism and the Animal. In M. Phillips \& N. Rumens (Eds.), Contemporary Perspectives on Ecofeminism (pp. 38-56). New York: Routledge.

Duffy, C. A. (2015a). An Anthology of Poetry on Climate Change. The Guardian. http://www.theguardian.com/environment/2015/may/11/an-anthology-of-poetry-on-climate-change

Duffy, C. A. (2015b). Parliament. The Guardian. http://www.theguardian.com/environment/2015/mar/27/keep-it-in-the-ground-a-poem-by-carol-annduffy

Gagliano, M. (2013). The Flowering of Plant Bioacoustics: How and Why? Behavioral Ecology, 1-2. doi: 10.1093/beheco/arto21

Gagliano, M., Mancuso, S., \& Robert, D. (2012). Towards Understanding Plant Bioacoustics. Trends in Plant Science, 17 (6), 323-325. doi: 10.1016/j.tplants.2012.03.002

Gagliano, M., Renton, M., Depczynski, M., \& Mancuso, S. (2014). Experience Teaches Plants to Learn Faster and Forget Slower in Environments Where It Matters. Oecologia, 175, 63-72. doi: 10.1007/soo442-0132873-7 
Glück, L. (1992). The Wild Iris. New York: HarperCollins.

Hall, M. (2009). Plant Autonomy and Human-Plant Ethics. Environmental Ethics, 31, 169-181.

Haraway, D. (2008). When Species Meet. Minneapolis, MN: University of Minnesota Press.

Huggan, G., \& Tiffin, H. (2010). Postcolonial Ecocriticism: Literature, Animals, Environment. New York: Routledge.

Johns-Putra, A. (2016). Climate Change in Literature and Literary Studies: From Cli-fi, Climate Change Theater and Ecopoetry to Ecocriticism and Climate Change Criticism. WIREs Climate Change, 7, 266282. doi: $10.1002 /$ wcc. 385

Kramshøj, M., Vedel-Petersen, I., Schollert, M., Rinnan, Å., Nymand, J., Ro-Poulsen, H., \& Rinnan, R. (2016). Large Increases in Arctic Biogenic Volatile Emissions Are a Direct Effect of Warming. Nature Geoscience, 9, 349-352. doi: 10.1038/ngeo2692

Laist, R. (Ed.). (2013). Plants and Literature: Essays in Critical Plant Studies. Amsterdam: Rodopi.

Marder, M. (2013). Plant-Thinking: A Philosophy of Vegetal Life. New York: Columbia University Press.

Mazzolai, B., \& Mancuso, S. (2013). Smart Solutions from the Plant Kingdom. Bioinspiration E Biomimetics, 8(2), 1-2. doi: 10.1088/1748-3182/8/2/020301

Milkoreit, M. (2016). The Promise of Climate Fiction: Imagination, Storytelling, and the Politics of the Future. In P. Wapner \& H. Elver (Eds.), Reimagining Climate Change (pp. 171-19o). London: Routledge.

Morton, T. (2013). Hyperobjects: Philosophy and Ecology after the End of the World. Minneapolis, MN: University of Minnesota Press.

Murray, L. (2007). Selected Poems. Melbourne: Black Inc.

Nealon, J. (2015). Plant Theory: Biopower and Vegetable Life. Palo Alto, CA: Stanford University Press.

Omasa, R., Kai, K., Uchijima, Z., \& Yoshino, M. (Eds.). (2013). Climate Change and Plants in East Asia. Tokyo: Springer-Verlag.

Oswald, A. (2015). Vertigo. The Guardian. http://www.theguardian.com/environment/2015/may/11/vertigoby-alice-oswald

Parmesan, C., \& Hanley, M. (2015). Plants and Climate Change: Complexities and Surprises. Annals of Botany, 116(6), 849-864.

Plantoid Project. (2012). Overview. Retrieved 14 May, 2016, from http://www.plantoid-project.eu/

Pollan, M. (2013). The Intelligent Plant: Scientists Debate a New Way of Understanding Flora. The New Yorker, December 23 E 30, 92-105.

Reich, P., Sendall, K., Stefanski, A., Wei, X., Rich, R., \& Montgomery, R. (2016). Boreal and Temperate Trees Show Strong Acclimation of Respiration to Warming. Nature, 531, 633-636. doi: 10.1038/nature17142

Rozema, J., Aerts, R., \& Cornelissen, H. (Eds.). (2006). Plants and Climate Change. Dordrecht: Springer.

Ryan, J. (2012). Green Sense: The Aesthetics of Plants, Place and Language. Oxford: TrueHeart Press.

Shapiro, K., \& DeMello, M. (2010). The State of Human-Animal Studies. Society \& Animals, 18(3), 2-17.

Siewers, A. (2011). Ecopoetics and the Origins of English Literature. In S. LeMenager, T. Shewry \& K. Hiltner (Eds.), Environmental Criticism for the Twenty-First Century (pp. 105-120). New York: Routledge.

Singer, P. (1975). Animal Liberation: A New Ethics for Our Treatment of Animals. New York: Random House.

Thoreau, H. (1993). Faith in a Seed: The Dispersion of Seeds and Other Late Natural History Writings. Washington, DC: Island Press. 
Thoreau, H. D. (2000). Wild Fruits: Thoreau's Rediscovered Last Manuscript. New York: W. W. Norton.

Tompkins, P., \& Bird, C. (1974). The Secret Life of Plants. New York: Avon.

Trewavas, A. (2002). Mindless Mastery. Nature, 415, 841.

Trewavas, A. (2014). Plant Behaviour and Intelligence. Oxford: Oxford University Press.

Vieira, P., Gagliano, M., \& Ryan, J. (2016). Introduction. In P. Vieira, M. Gagliano \& J. Ryan (Eds.), The Green Thread: Dialogues with the Vegetal World (pp. ix-xxvii). Lanham, MD: Lexington Books.

Wonder, S. (1979). Stevie Wonder's Journey through The Secret Life of Plants. I.A.M. Studios, Irvine, CA Tamla.

Wyndham, J. (1986). The Day of the Triffids. New York: Ballantine Books. 